\title{
Atmospheric oxygenation of the early earth and earth-like planets driven by competition between land and seafloor weathering
}

\author{
Yasuto Watanabe* (10) and Eiichi Tajika(1)
}

\begin{abstract}
Oxygen is a potential biosignature for terrestrial Earth-like planets. The primary source of oxygen on Earth is oxygenic photosynthesis, which may be limited by the supply of riverine phosphorus. Therefore, phosphorus supply from the chemical weathering of continents is crucial for the evolution of $\mathrm{pO}_{2}$. Chemical weathering occurs on both the continents and seafloor and stabilizes the climate, but phosphorus is only supplied by continental weathering. The amount of continental weathering relative to seafloor weathering may be critical for primary productivity and $\mathrm{pO}_{2}$. The area of continents could change as a result of continental growth and the amount of ocean mass on the planetary surface, and these factors could be very different on extrasolar Earth-like planets. Here, we investigated the effects of continental and seafloor weathering on the atmospheric oxygen levels, in terms of the Earth-like phosphoruslimited marine biosphere. We used a simple biogeochemical model and investigated a possible relationship between continental growth and atmospheric oxygen levels. We found that the atmosphere could evolve totally different redox conditions (an abrupt rise of atmospheric oxygen levels or a reducing condition to form organic haze) caused by continental growth, which changes the relative contribution of silicate weathering feedback from seafloor to continent. We also found that conditions with lower solar luminosity and a larger land fraction provided a preferable condition for the phosphorus-limited marine biosphere to produce high levels of oxygen in the atmosphere. We also found that the atmospheric oxygen level is strongly affected by the activity of the anaerobic marine microbial ecosystem. Our results suggest that the area of land on the planetary surface may be crucial for achieving high oxygen levels in a phosphorus-limited marine biosphere. These results contribute to the fundamental understanding of the general behaviors of Earth-like planets with oceans and an Earth-like marine biosphere.
\end{abstract}

Keywords: Biogeochemistry, Silicate weathering, Atmosphere evolution, Organic haze

\section{Introduction}

Oxygen is produced from oxygenic photosynthesis on land and in the ocean, and comprises $21 \%$ of the present atmosphere. In the history of the Earth, atmospheric oxygen level $\left(p \mathrm{O}_{2}\right)$ substantially increased from extremely low $\left(p \mathrm{O}_{2}<10^{-6}\right.$ present atmospheric level; PAL) to a weakly oxidized condition $\left(\sim 10^{-2}\right.$ PAL $)$ around 2.4-2.1 Ga, which is called the Great Oxidation

\footnotetext{
*Correspondence: yasuto@eps.s.u-tokyo.ac.jp

Department of Earth and Planetary Science, Graduate School of Science,

The University of Tokyo, Hongo 7-3-1, Bunkyo-ku, Tokyo 113-0033, Japan
}

Event (GOE) (e.g., Lyons et al. 2014; Catling and Zahnle 2020). The trigger of the GOE is vigorously debated (Catling et al. 2001; Holland 2006; Claire et al. 2006; Kump and Barley 2007; Kump 2008; Gaillard et al. 2011; Kasting 2013; Kipp et al. 2020; Kadoya et al. 2020), and it is likely that the source of oxygen due to oxygenic photosynthesis must have exceeded the sink of oxygen to trigger the GOE. On the modern Earth, the net primary productivity of oxygenic photosynthesis in marine and land ecosystems is $\sim 4 \times 10^{15} \mathrm{~mol} \mathrm{C}$ year $^{-1}$ and $\sim 5 \times 10^{15}$ mol $C$ year $^{-1}$, respectively (Field et al. 1998; Sarmiento and Gruber 2002). Before the 
evolution of land plants in the Phanerozoic, marine ecosystems accounted for most of the oxygen flux supplied to the atmosphere (e.g., Lenton et al. 2016). Global marine primary productivity in the present ocean may be limited by the supply of riverine phosphorus (Tyrrell 1999), so phosphorus supply from the weathering of continental phosphorus-hosted minerals, such as apatite, is crucial for the evolution of $p \mathrm{O}_{2}$ (Hao et al. 2020a, b). Weathering proceeds on continents and seafloor, both of which could stabilize the climate through the silicate weathering negative feedback (e.g., Walker et al. 1981; Krissansen-Totton and Catling 2017; Krissansen-Totton et al. 2018). In particular, the fundamental role of seafloor weathering for climate regulation has recently gained attention in understanding the stability of the climate on Earth and Earth-like exoplanets (e.g., Krissansen-Totton and Catling 2017; Krissansen-Totton et al. 2018; Hao et al. 2020b; Hayworth and Foley 2020). Phosphorus is derived from chemical weathering of the phosphorus-hosted minerals on continental crusts, but is not derived from the oceanic crust by seafloor weathering (Wheat et al. 1996; Paytan and McLaughlin 2007; Hao et al. 2020b). Therefore, changes in the land fraction and the climate should affect the supply rate of phosphorus to the ocean, which, in turn, affect marine primary productivity.

Preceding the GOE, the mass of continental crusts may have increased since the mid-late Archean (3.5-2.5 Ga) (e.g., Taylor and McLennan 1995; Hawkesworth and Kemp 2006; Korenaga et al. 2017). It has been discussed that the increase in the continental crust would have contributed to accumulation of oxygen in the atmosphere through an increased phosphorus supply from the continent (e.g., Godderis and Veizer 2000; Flament et al. 2013; Korenaga et al. 2017; Eguchi et al. 2020; Hao et al. 2020a, b), an increased contribution of subaerial volcanism (Kump and Barley 2007; Gaillard et al. 2011), a change in the chemical composition of continental crusts (Lee et al. 2016; Cox et al. 2018), or a decrease in reduced metamorphic gases due to oxidation of continents in association with hydrogen escape to space (Catling et al. 2001). While the different roles of the continental and seafloor weathering in the marine phosphorus budget of the early Earth have been established (Hao et al. 2020b), the conditions for atmospheric oxygenation driven by changes in the relative contributions of continental and seafloor weathering in association with tectonic, climatic, and biological evolution in the early Earth have not been systematically assessed. In the broader context of Earth-like planets, land fraction, volcanic activities, and the resulting climate could vary with large uncertainty, which could affect atmospheric composition through competition between continental and seafloor weathering if a planet is inhabited by an Earth-like phosphorus-limited marine biosphere.

In this paper, we focused on the conditions required to cause biologically driven transition of the atmospheric composition (e.g., accumulation of oxygen in the atmosphere) of the Earth and Earth-like planets with a phosphorus-limited marine biosphere. We examine how the relative contributions of continental and seafloor weathering change with climatic, tectonic, and biological evolutions, and consider how such changes might contributes to transition of the atmospheric composition of the early Earth and Earth-like planets.

\section{Methods}

We considered an early Earth environment and employed a simplified equilibrium ocean box model, which simplified the time-dependent model of Harada et al. (2015) (Fig. 1). We improved the model to be suitable for a calculation of a long-term steady state of four components in the atmosphere-ocean system $\left(\mathrm{CO}_{2}, \mathrm{O}_{2}, \mathrm{CH}_{4}\right.$, and $\left.\left[\mathrm{PO}_{4}\right]^{3-}\right)$, including the introduction of seafloor weathering and the greenhouse effect of $\mathrm{CH}_{4}$ and $\mathrm{C}_{2} \mathrm{H}_{6}$, which were not considered in the model of Harada et al. (2015). The global carbon budget in the atmosphere-ocean system is expressed as follows:

$$
F_{\mathrm{d}}=F_{\mathrm{ws}}+F_{\mathrm{sws}} \text {. }
$$

The $\mathrm{CO}_{2}$ source is outgassing from the interior of the Earth $\left(F_{\mathrm{d}}\right)$, while the $\mathrm{CO}_{2}$ sink includes continental weathering $\left(F_{\mathrm{ws}}\right)$ and seafloor weathering $\left(F_{\mathrm{sws}}\right)$. Our focus is on the long-term stability of the system, so the burial of organic carbon is assumed to be balanced with the $\mathrm{CO}_{2}$ input via decomposition of organic carbon by metamorphism-volcanism. The rate of silicate weathering on land is represented as follows (Krissansen-Totton and Catling 2017; Krissansen-Totton et al. 2018):

$\frac{F_{\mathrm{ws}}}{F_{\mathrm{ws}, 0}}=f_{\mathrm{a}} f_{\mathrm{e}}\left(\frac{p \mathrm{CO}_{2}}{p \mathrm{CO}_{2,0}}\right)^{\beta} \exp \left(\frac{-\mathrm{E}_{\text {cont }}}{\mathrm{R}}\left(\frac{1}{\mathrm{~T}_{\mathrm{s}}}-\frac{1}{\mathrm{~T}_{\mathrm{s}, 0}}\right)\right)$,

where $p \mathrm{CO}_{2}$ is the atmospheric $\mathrm{CO}_{2}$ level, $T_{\mathrm{s}}$ is the global mean surface temperature, $R$ is the gas constant, $f_{\mathrm{e}}$ is the efficiency of soil biological activity relative to present, $f_{\mathrm{a}}$ is the land fraction relative to present $(30 \%$ of the Earth's surface), $\beta$ is an exponent assumed to be 0.3 , and $E_{\text {cont }}$ represents an effective activation energy for the continental weathering of silicate minerals $\left(20 \mathrm{~kJ} \mathrm{~mol}^{-1}\right)$ (Riebe et al. 2004; Krissansen-Totton and Catling 2017). The subscript 0 represents the modern value (Additional file 1: Table S1). The effect of the uncertainty in the values of $\beta$ and $E_{\text {cont }}$ is shown in the Additional file 1: Figs. S1 and S2. The value of $f_{\mathrm{e}}$ is fixed at 0.15 , assuming no 


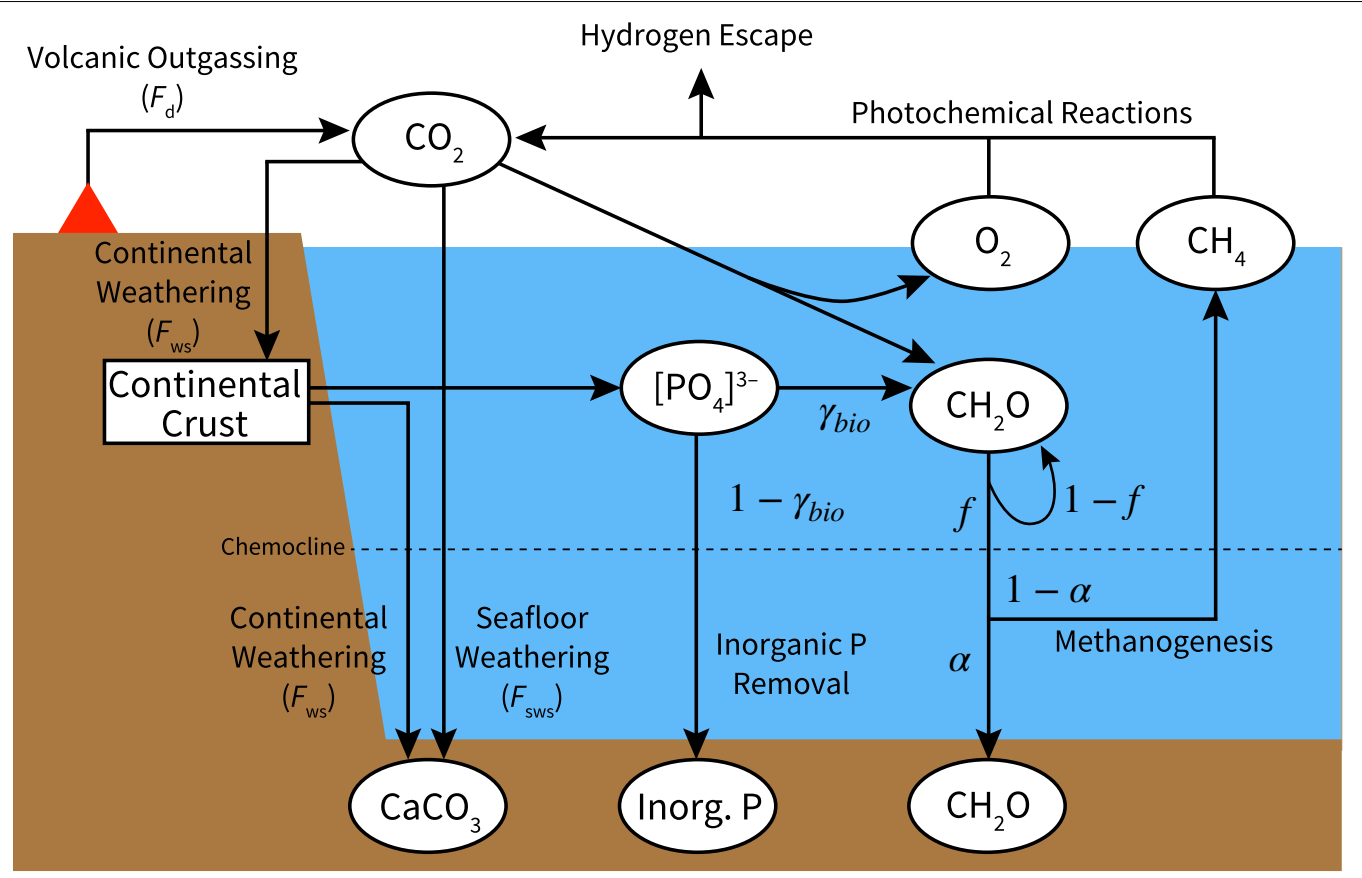

Fig. 1 Schematic diagram of the simplified steady-state ocean box model. Arrows represent a net chemical flux

vascular plants on land (Berner 1994; Drever and Zobrist 1992). The effect of continental growth is assumed to be reflected on an aerial land fraction because physical erosion of submerged continents is small (e.g., Glaser et al. 2020). We varied the value of $f_{\mathrm{a}}$ to represent an increase in the land fraction. The surface temperature is estimated using a parameterization of the greenhouse effect of $\mathrm{CO}_{2}$, $\mathrm{H}_{2} \mathrm{O}, \mathrm{CH}_{4}$, and $\mathrm{C}_{2} \mathrm{H}_{6}$ based on Lehmer et al. (2020) and Haqq-Misra et al. (2008) (Additional file 1).

The rate of seafloor weathering is represented as follows (Krissansen-Totton and Catling 2017; KrissansenTotton et al. 2018):

$$
\frac{F_{\text {sws }}}{F_{\text {sws }, 0}}=r_{\text {spr }}\left(\frac{\left[H^{+}\right]_{\text {pore }}}{\left[H^{+}\right]_{\text {pore }, 0}}\right)^{\gamma} \exp \left(\frac{-E_{\text {diss }}}{\mathrm{R}}\left(\frac{1}{\mathrm{~T}_{\text {pore }}}-\frac{1}{\mathrm{~T}_{\text {pore }, 0}}\right)\right),
$$

where $r_{\mathrm{spr}}$ is the spreading rate of the ocean crust relative to present; $\left[\mathrm{H}^{+}\right]_{\text {pore }}$ and $T_{\text {pore }}$ are the hydrogen ion concentration and temperature in the pore space of ocean crust, respectively; $\gamma$ is the exponent of the dissolution of seafloor basalt (0.25); and $E_{\text {diss }}$ is the effective activation energy of basalt $\left(80 \mathrm{~kJ} \mathrm{~mol}^{-1}\right)$ (Coogan and Dosso 2015; Krissansen-Totton et al. 2018). The effect of the uncertainty in the values of $\gamma$ and $E_{\text {diss }}$ is shown in the Additional file 1: Figs. S1 and S2. We used a simplified relationship between pore space $\mathrm{pH}$ in the oceanic crust and $p \mathrm{CO}_{2}$ in the atmosphere, which is derived based on the regression of the results of numerous simulations using a global carbon cycle model coupled with geochemical processes in the pore space of seafloor basalt (Krissansen-Totton et al. 2018):

$$
\left[H^{+}\right]_{\text {pore }}=\left(10^{-8.44} \times p \mathrm{CO}_{2}\right)^{\frac{1}{1.34}} \text {. }
$$

The marine phosphorus budget can be derived by solving the mass balance equation of phosphorus in a steady state, assuming a bioavailable fraction of riverine phosphorus $\left(\gamma_{\text {bio }}\right)$, which is the fraction of phosphorus ultimately consumed by the marine biosphere (subsequently removed as organic matter), and considering that phosphorus is also partly removed as inorganic compounds in the ocean and seafloor and partly recycled from buried sediment:

$$
\gamma_{\mathrm{bio}} F_{\mathrm{rp}}=\frac{\alpha}{R_{\mathrm{cp}, \mathrm{bur}}} F_{\mathrm{po}}
$$

where $F_{\mathrm{rp}}$ is the riverine phosphorus supply rate; $F_{\mathrm{po}}$ is the export production rate from the surface ocean (mol $C$ year $\left.^{-1}\right) ; \alpha$ is the burial efficiency of exported organic carbon from the surface water $(\alpha=0.2)$ assuming a value of the burial efficiency of organic carbon $\left(f_{\mathrm{po}} \cdot \alpha\right)$ of 0.02 , which is similar to the value observed in the Black Sea (Betts and Holland 1991), where $f_{\text {po }}$ is the export production efficiency $\left(f_{\mathrm{po}}=0.1\right) ; R_{\mathrm{cp} \text {,bur }}$ is the C:P ratio of organic matter buried in sediment $\left(R_{\mathrm{cp}, \mathrm{bur}}=300\right)$, which 
is an observed value in the euxinic basin (Algeo and Ingall 2007; Laakso and Schrag 2019) but could have been even larger in the anoxic Archean ocean (Reinhard et al. 2017). It should be noted that this value could be larger than the Redfield ratio (C:P 106:1) because of two different processes: release of phosphorus from organic carbon buried in the sediment to anoxic deep water, and larger C:P ratio of organic matter produced by primary producers under the condition of phosphorus scarcity in the ocean. We also assumed that all riverine phosphorus is ultimately utilized by the marine biosphere $\left(\gamma_{\text {bio }}=1\right)$. The dependency of the result on these parameters is discussed in Sect. 3.4. We assumed that the rates of continental weathering of both carbonate minerals $\left(F_{\mathrm{wc}}\right)$ and phosphorus-hosted minerals (hence, riverine phosphorus supply, $\left.F_{\mathrm{rp}}\right)$, are proportional to the rates of continental silicate weathering:

$$
\frac{F_{\mathrm{rp}}}{F_{\mathrm{rp}, 0}}=\frac{F_{\mathrm{wc}}}{F_{\mathrm{wc}, 0}}=\frac{F_{\mathrm{ws}}}{F_{\mathrm{ws}, 0}} .
$$

This assumption is based on estimates of predominantly transport-limited continental weathering, which is also reflected in the low value of $E_{\text {cont }}$ (Riebe et al. 2004; Krissansen-Totton and Catling 2017).

The export production from the surface ocean $\left(F_{\mathrm{po}}\right)$ is estimated from the phosphorus concentration in the surface ocean $\left(\left[\mathrm{PO}_{4}\right]^{3-}{ }_{s}\right.$ in mol L ${ }^{-1}$ ) (Yamanaka and Tajika 1996):

$$
F_{\mathrm{po}}=R_{\mathrm{cp}, \mathrm{bio}} V_{\mathrm{s}}\left[\mathrm{PO}_{4}\right]_{\mathrm{s}}^{3-} \cdot \frac{\left[\mathrm{PO}_{4}\right]_{s}^{3-}}{\left[\mathrm{PO}_{4}\right]_{s}^{3-}+\gamma_{\mathrm{p}}}\left(\mathrm{mol} \mathrm{Cyear}^{-1}\right),
$$

where $V_{\mathrm{s}}$ is the volume of the surface ocean $\left(5.0 \times 10^{19}\right.$ $\mathrm{L}), R_{\mathrm{cp}, \mathrm{bio}}$ is the C:P ratio of organic matter produced by primary producers $\left(R_{\mathrm{cp}, \mathrm{bio}}=106\right)$, and $\gamma_{\mathrm{p}}$ is the half saturation constant for the export production $\left(1.0 \times 10^{-6} \mathrm{~mol}\right.$ $\left.\mathrm{L}^{-1}\right)$. The rate of primary production $\left(F_{\mathrm{pp}}\right)$ is estimated from the export production (Harada et al. 2015):

$$
F_{\mathrm{pp}}=\frac{1}{f_{\mathrm{po}}} F_{\mathrm{po}}
$$

Using Eqs. (5), (7), and (8), the phosphorus concentrations in the surface ocean and the primary productivity are calculated. We assumed that primary production is performed by both oxygenic photoautotrophs $\left(F_{\text {oph }}\right)$ and anoxygenic photoautotrophs $\left(F_{\text {red }}\right)$, which use reduced compounds in the ocean as electron donors (e.g., $\mathrm{H}_{2}$ and $\left.\mathrm{Fe}^{2+}\right)$.

$$
F_{\mathrm{pp}}=F_{\mathrm{oph}}+F_{\text {red }} \text {. }
$$

These groups can coexist in the ocean because some anoxygenic photoautotrophs can photosynthesize in the deeper part of the photic zone (e.g., Ozaki et al. 2019). We treated the primary productivity of anoxygenic photoautotrophs as a fixed parameter, assuming that the supply of electron donors (e.g., $\mathrm{H}_{2}$ and $\mathrm{Fe}^{2+}$ ) limited the primary productivity of anoxygenic photoautotrophs. We assumed two values for $F_{\text {red }}$ one is for the Proterozoiclike biosphere, where most primary production is conducted by oxygenic photosynthesis $\left(F_{\text {red }}=7.5 \times 10^{10} \mathrm{~mol}\right.$ C year ${ }^{-1}$ ), which is similar to the modern hydrothermal input rate of iron (Holland 2006; Goldblatt et al. 2006). The other is the Archean-like biosphere, where the primary productivity by anoxygenic photoautotrophs is assumed to be larger $\left(F_{\text {red }}=2.0 \times 10^{13} \mathrm{~mol} \mathrm{C}\right.$ year $\left.^{-1}\right)$, because the iron input flux is large and the recycling of $\mathrm{H}_{2}$ is amplified by the photo-dissociation of methane in the atmosphere (e.g., Ozaki et al. 2018). The atmospheric methane and oxygen levels were calculated from $F_{\mathrm{pp}}$ and $F_{\text {red }}$ using a simplified parameterization of the atmospheric methane oxidation rate (Goldblatt et al. 2006; Harada et al. 2015).

\section{Results and discussion}

\section{Climate-dependent riverine phosphorus supply}

First, we showed the dependence of the riverine phosphorus supply rate on climate warming caused by increases in $p \mathrm{CO}_{2}$ and $p \mathrm{CH}_{4}$ (Fig. 2A-D). With an increase in $p \mathrm{CO}_{2}$ and surface temperature, the rate of riverine phosphorus input increases with increased continental weathering rate (Fig. 2C; solid line) (Hao et al. 2020a, b). However, the dependence on climate warming is different when it is driven by an increase in $p \mathrm{CH}_{4}$ (Fig. $2 \mathrm{E}-\mathrm{H}$ ). As the $\mathrm{CH}_{4}$ level increases, the surface temperature increases but $p \mathrm{CO}_{2}$ decreases as a result of the negative feedback of silicate weathering against warming caused by $\mathrm{CH}_{4}$ (Fig. 2E, F). In the case of $\mathrm{CH}_{4}$-induced warming, the continental weathering rate decreases despite climate warming (Fig. 2G; solid lines), which leads to the decrease in the phosphorus supply rate (Fig. $2 \mathrm{H}$ ). This different sensitivity arises primarily from the difference in the dependencies of continental and seafloor weathering on $p \mathrm{CO}_{2}$. The $p \mathrm{CO}_{2}$ dependence of seafloor weathering is weak because it is dependent on the pore space $\mathrm{pH}$ as in Eq. (3). The difference is also enhanced by different effective activation energy of continental and seafloor weathering. Because seafloor weathering becomes effective compared with continental weathering under lower $p \mathrm{CO}_{2}$ and higher temperature, $\mathrm{CH}_{4}$-induced 

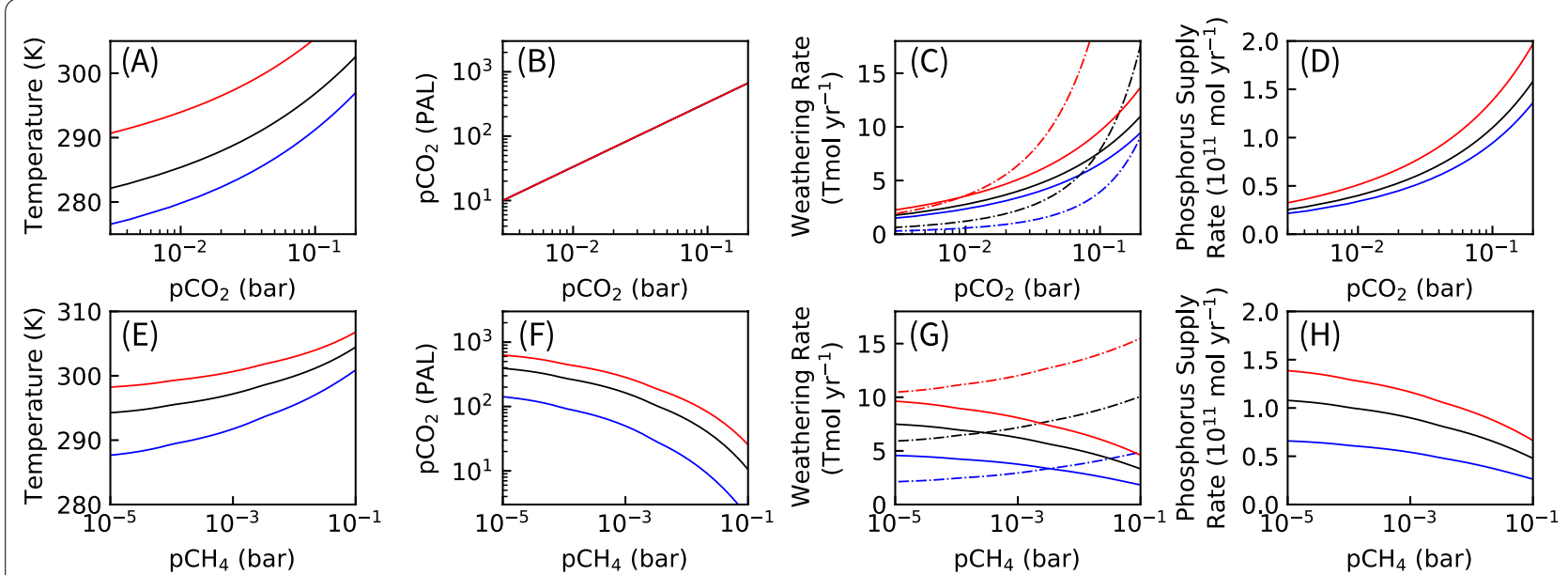

Fig. 2 Relationship between climate warmings and riverine phosphorus supply rate. Response of $\mathbf{A}$ the surface temperature (K); $\mathbf{B}$ atmospheric $\mathrm{CO}_{2}$ level (present atmospheric level; PAL); $\mathbf{C}$ continental/seafloor weathering rate ( $\mathrm{Tmol}_{\mathrm{mear}}{ }^{-1}$ ) (solid line/dot-dashed line), and $\mathbf{D}$ the riverine phosphorus supply rate $\left(10^{11}\right.$ mol year $\left.{ }^{-1}\right)$ to $\mathrm{CO}_{2}$-induced warming at a fixed $p \mathrm{CH}_{4}$ (blue: $1.00 \times 10^{-6}$ (bar), black: $1.00 \times 10^{-4}(\mathrm{bar})$, red: $3.00 \times 10^{-3}$ (bar)). Similarly, response of $\mathbf{E}$ the surface temperature (K); $\mathbf{F}$ atmospheric $\mathrm{CO}_{2}$ level (PAL); $\mathbf{G}$ continental/seafloor weathering rate $\left(\mathrm{Tmol}^{-1}\right.$ year $\left.{ }^{-1}\right)$, and $\mathbf{H}$ the riverine phosphorus supply rate $\left(10^{11} \mathrm{~mol}_{\text {year }}{ }^{-1}\right)$ to $\mathrm{CH}_{4}$-induced warming at a fixed $\mathrm{CO}_{2}$ outgassing rate (blue: $6.7 \mathrm{Tmol}^{\text {year }}{ }^{-1}$, black: 13.4 $\mathrm{Tmol}_{\text {year }}{ }^{-1}$, red: $20.1 \mathrm{Tmol}_{\text {year }}{ }^{-1}$ ). These calculations are conducted with solar luminosity (83\% of present Earth), seafloor spreading rate (1.307 times the present rate), soil biological activity $\left(f_{\mathrm{e}}=0.15\right)$, and present continental area $\left(f_{\mathrm{a}}=1\right)$

warming causes seafloor weathering to be important in climate regulation. As a result, the phosphorus supply caused by continental weathering responds differently to $\mathrm{CO}_{2}$-induced or $\mathrm{CH}_{4}$-induced warming. This result suggests the importance of the competition between continental and seafloor weathering in controlling the phosphorus input rate and the global marine primary productivity.

\section{Atmospheric evolution driven by continental growth}

Next, we showed the effect of continental growth (i.e., an increase of land area) on the atmospheric oxygen
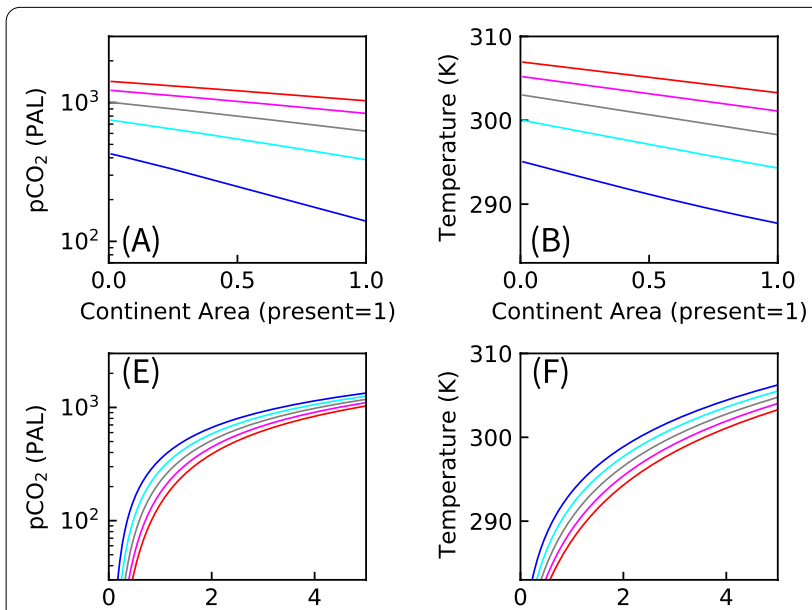

$\mathrm{CO}_{2}$ Outgassing Flux (present $=1$ ) $\mathrm{CO}_{2}$ Outgassing Flux (present $=1$ )
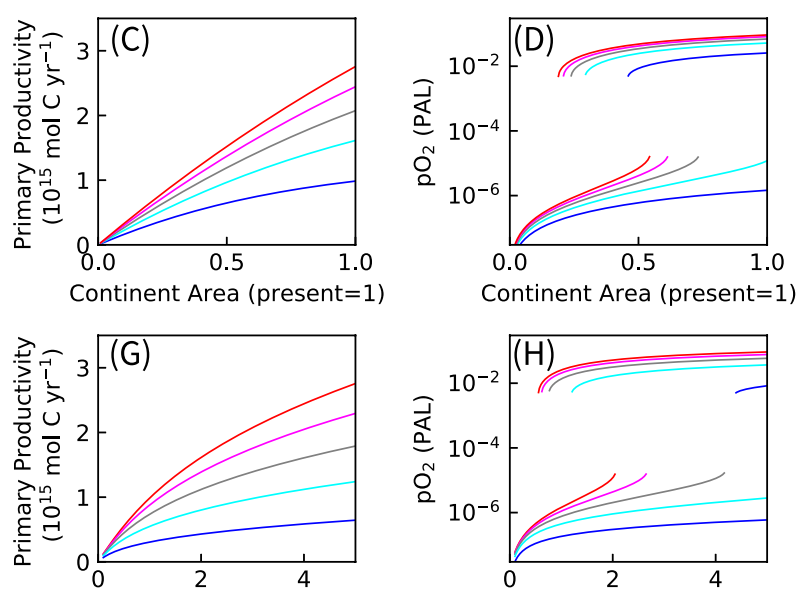

Fig. 3 Response of the system against continental growth with Proterozoic-like ecosystem. The dependence of $p \mathrm{CO}_{2}$, surface temperature, export production rate, and $\mathrm{pO}_{2}(\mathrm{PAL})$ on the continental area $(\mathbf{A}-\mathbf{D})$ and $\mathrm{CO}_{2}$ outgassing flux $(\mathbf{E}-\mathbf{H})$, calculated for low primary productivity of anaerobic photoautotrophs $\left(F_{\text {red }}=7.50 \times 10^{10} \mathrm{~mol} \mathrm{C} \mathrm{year}{ }^{-1}\right)$, bioavailable fraction of the riverine phosphorus $\left(\gamma_{\text {bio }}=1\right)$, solar luminosity $(83 \%$ of present Earth), seafloor spreading rate (1.307 times the present rate), and soil biological activity $\left(f_{\mathrm{e}}=0.15\right)$. A-D The dependence on the continental area at different $\mathrm{CO}_{2}$ outgassing rates. Steady states for $1,2,3,4$, and 5 times the present $\mathrm{CO}_{2}$ outgassing rate are shown with blue, cyan, grey, pink, and red lines, respectively. $\mathbf{E}-\mathbf{H}$ The dependence on $\mathrm{CO}_{2}$ outgassing rate at different continental areas. Steady states for $0.2,0.4,0.6,0.8$, and 1.0 times the present continental area of the Earth are shown with blue, cyan, grey, pink, and red lines, respectively 
level (Fig. 3A-D). In this calculation, we assumed a Proterozoic-like ecosystem, where the primary productivity of the anaerobic photoautotrophs is small $\left(F_{\text {red }}=7.50 \times 10^{10} \mathrm{~mol} \mathrm{C}\right.$ year $\left.^{-1}\right)$. The colored lines in Fig. 3A-D represent the steady states at different $\mathrm{CO}_{2}$ outgassing rates (1-5 times higher relative to present). With a small land fraction $\left(f_{\mathrm{a}} \sim 0\right), p \mathrm{O}_{2}$ is low $\left(<1.0 \times 10^{-7} \mathrm{PAL}\right)$ at any $\mathrm{CO}_{2}$ outgassing rate (Fig. 3D) because the riverine phosphorus supply from continental weathering would be very limited (Hao et al. 2020b). As the land area increases, $p \mathrm{CO}_{2}$ and the surface temperature decrease because the continental weathering efficiency increases with increasing land area. The increased continental weathering efficiency caused by the increased land area drives changes in the equilibrium climate state, and the riverine phosphorus input increases with decreasing $p \mathrm{CO}_{2}$ and surface temperature; this is different from the sensitivity experiments in Fig. 2A-D because the continental weathering efficiency is constant in Fig. 2. As a result, the marine primary productivity and $p \mathrm{O}_{2}$ increase with the continental growth (Fig. 3C-D).

When the $\mathrm{CO}_{2}$ outgassing rate is comparable to the present condition, the atmospheric oxygen level is kept low $\left(p \mathrm{O}_{2}<10^{-5} \mathrm{PAL}\right)$ even with the present land area $\left(f_{\mathrm{a}}=1.0\right)$ (lower blue line in Fig. 3D). However, when the $\mathrm{CO}_{2}$ outgassing rate is more than 2 times the present level, an equilibrium level of atmospheric oxygen increases abruptly to a higher equilibrium level when land area reaches a critical size during continental growth (grey, pink, and red lines in Fig. 3D).

The lifetime of atmospheric oxygen increases nonlinearly as a result of UV shielding by the development of an ozone layer, which is formed from oxygen at an atmospheric oxygen level above $\sim 10^{-5} \mathrm{PAL}$, causing bistability of atmospheric oxygen levels against primary productivity (Goldblatt et al. 2006). Thus, transition from the low to the high oxygen branch could occur when primary productivity increases to a critical level. Once the high $p \mathrm{O}_{2}$ state is achieved, the high $p \mathrm{O}_{2}$ branch could be maintained with a smaller rate of production of oxygen to the atmosphere than that required for the onset of the abrupt rise of atmospheric oxygen from the low $p \mathrm{O}_{2}$ branch (Fig. 3D, H). Consequently, high equilibrium levels of atmospheric oxygen could exist even at the present $\mathrm{CO}_{2}$ outgassing rate when the land area exceeds $\sim 50 \%$ of the present area (upper blue line in Fig. 3D). Even if oxygenation from the low to the high oxygen branch were not driven by continental growth with a small $\mathrm{CO}_{2}$ outgassing rate, the existence of the high oxygen branch would allow atmospheric oxygenation after the snowball Earth event, driven by extremely large primary productivity attributable to transient warming caused by accumulation of $\mathrm{CO}_{2}$ during the snowball glaciation, as discussed in Harada et al. (2015). With a sufficient $\mathrm{CO}_{2}$ outgassing rate, oxygenation could have been driven without a snowball Earth event; otherwise, climatic perturbation after the snowball Earth event might have been necessary to trigger oxygenation.

The existence of the bistability of $p \mathrm{O}_{2}$ depends on assumptions that affect the net supply rate of oxygen or methane to the atmosphere (e.g., methanotroph activity in the surface ocean) (Daines and Lenton 2016). However, recent simulations with 1-D photochemical models suggest that the bistability of $p \mathrm{O}_{2}$ against the oxygen flux from the ocean could exist if the ratios of methane and oxygen flux are dependent on $p \mathrm{O}_{2}$ through changes in the marine sulfate concentration (Gregory et al. 2021). Therefore, although the bistability of atmospheric oxygen level should be evaluated with a more sophisticated ecosystem model, we suggest that the existence of bistability helped to maintain the high atmospheric oxygen level $\left(p \mathrm{O}_{2}>\sim 10^{-2} \mathrm{PAL}\right)$ after its abrupt rise.

The dependence of the atmospheric oxygen level on the $\mathrm{CO}_{2}$ outgassing rate is shown in Fig. $3 \mathrm{E}-\mathrm{H}$. Colored lines represent a different land fraction $\left(f_{\mathrm{a}}=0.2,0.4,0.6\right.$, 0.8 , and 1.0). With the present land fraction $\left(f_{\mathrm{a}}=1.0\right.$; red line), the lower equilibrium levels of atmospheric oxygen abruptly disappears when the $\mathrm{CO}_{2}$ outgassing rate exceeds $\sim 2.0$ times the present level. Because of the bistability of atmospheric oxygen levels, high equilibrium levels of oxygen could be sustained with a smaller $\mathrm{CO}_{2}$ outgassing rate after the abrupt increase in $p \mathrm{O}_{2}$, for example, owing to a transient increase in the $\mathrm{CO}_{2}$ outgassing rate. This result suggests that if the land area reached the present size in the late Archean to early Proterozoic, oxygenation could have been driven by an increase in $\mathrm{CO}_{2}$ outgassing (and climate warming) which is caused by increased volcanic activity over a period of geological timescale $\left(\sim 10^{6}\right.$ years). Therefore, increased continental area and volcanic activity (hence, $\mathrm{CO}_{2}$ outgassing rate) is preferable for a phosphorus-limited marine biosphere to achieve a high oxygen level.

\section{Formation of an organic haze layer driven by continental growth}

The large $\mathrm{CH}_{4}$ flux condition, as considered in the Archean Earth system, could have been amplified through the recycling of hydrogen by anoxygenic photoautotrophs (Ozaki et al. 2018). Under such conditions, the oxygenation of the atmosphere cannot occur even when the $\mathrm{CO}_{2}$ outgassing rate is very large $\left(F_{\mathrm{d}} / F_{\mathrm{d}, 0}=5\right)$ (Fig. $\left.4 \mathrm{C}\right)$ because riverine phosphorus accumulates in the ocean and is used preferentially by anoxygenic photoautotrophs in upwelling regions. This is because the Fe-based photoautotrophs can photosynthesize with smaller amount of sunlight at the deeper 

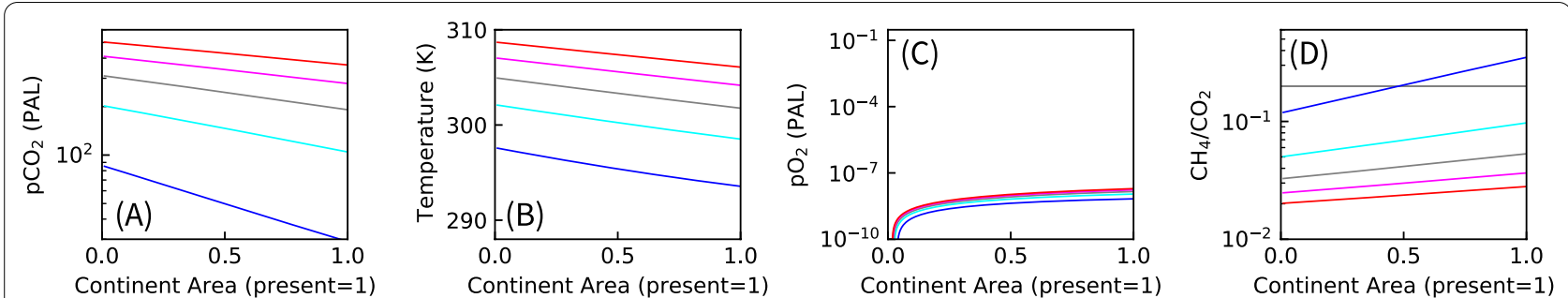

Fig. 4 Response of the system against continental growth with Archean-like ecosystem. The dependence of $\mathbf{A} p \mathrm{CO}_{2}, \mathbf{B}$ surface temperature, $\mathbf{C}$ $\mathrm{pO}_{2}$ (PAL), and $\mathbf{D} \mathrm{CH}_{4} / \mathrm{CO}_{2}$ ratio on the continental area, calculated in the case of high primary productivity of the anaerobic photoautotrophs $\left(F_{\text {red }}=2.00 \times 10^{13} \mathrm{~mol} \mathrm{C} \mathrm{year}^{-1}\right)$, bioavailable fraction of the riverine phosphorus $\left(\gamma_{\text {bio }}=1\right)$, solar luminosity ( $83 \%$ of the present Earth), seafloor spreading rate (1.307 times the present rate), and soil biological activity $\left(f_{e}=0.15\right)$. Dependence on continental area for $1,2,3,4$, and 5 times the present $\mathrm{CO}_{2}$ outgassing rate are shown with blue, cyan, grey, pink, and red lines, respectively

part of the photic zone than the oxygenic photoautotrophs like cyanobacteria, which live in the shallower part of the photic zone (Ozaki et al. 2019). Our result is consistent with the geological records, which suggest that low $p \mathrm{O}_{2}$ remained in the late Archean, even after the evolution of oxygenic photosynthesis. The activity of anoxygenic photosynthesis might have inhibited the spread of oxygenic photosynthesis until the GOE in the early Paleoproterozoic (e.g., Ozaki et al. 2019; Olejarz et al. 2021).

Under the high $\mathrm{CH}_{4}$ flux from the anaerobic marine biosphere, the evolution of continents could cause different consequences for atmospheric composition (Fig. 4A-D). With the present $\mathrm{CO}_{2}$ outgassing rate, the atmosphere reaches a highly reducing condition $\left(\mathrm{CH}_{4} / \mathrm{CO}_{2}>\sim 0.2\right)$ as the continental crust grows and an organic haze is formed (Fig. 4D blue line) (Pavlov et al. 2001; Arney et al. 2016). Atmospheric $\mathrm{CH}_{4}$ levels increase with the activity of anoxygenic photoautotroph, followed by the decomposition of organic carbon by methanogenesis in the deep ocean. As a result, $p \mathrm{CO}_{2}$ is lower than in the Proterozoic-like case (Fig. 3A) because the greenhouse effect of $\mathrm{CH}_{4}$ decreases the equilibrium $p \mathrm{CO}_{2}$ owing to the silicate weathering negative feedback (Fig. 2E-F). When the land area increases to more than $\sim 0.5$ times the present area with the present $\mathrm{CO}_{2}$ outgassing rate, formation of an organic haze layer could be driven in the atmosphere (Fig. 4D). Repeated haze-forming events have been suggested from the co-variation of carbon and sulfur isotopes during the late Archean (Zerkle et al. 2012; Izon et al. 2017). The continental growth in the mid-late Archean may have helped to form the organic haze layer when the $\mathrm{CO}_{2}$ outgassing rate is small.

In summary, the continental growth could cause a totally different atmospheric redox state, such as an abrupt increase in the atmospheric oxygen level (weakly oxidizing condition) or the formation of hydrocarbon haze (highly reducing condition), depending on anoxygenic photoautotroph activity and volcanic $\mathrm{CO}_{2}$ outgassing rate.

\section{Optimal conditions for the earth-like planets with high atmospheric oxygen level}

The responses of the phosphorus-limited biosphere and atmospheric oxygen levels are summarized in Fig. 5A-F. The blue-shaded and red-shaded areas represent the steady-state solutions of low and high $p \mathrm{O}_{2}$, respectively, and the purple-shaded area represents the conditions under which both the high and low $p \mathrm{O}_{2}$ states exist. As discussed above, large land area and/or high $\mathrm{CO}_{2}$ outgassing flux are required for high atmospheric oxygen levels with the phosphorus-limited marine biosphere (Fig. 5A). When the solar luminosity is high, $p \mathrm{O}_{2}$ tends to be low (Fig. 5B). This is because high solar luminosity causes climate warming as in the case of increased $p \mathrm{CH}_{4}$ (Fig. 2E-H), which results in low equilibrium $p \mathrm{CO}_{2}$ and hence the low continental weathering rate. This may suggest that Earth-like exoplanets near the inner edge of the habitable zone are not preferable for sustaining high atmospheric oxygen levels with an Earth-like phosphorus-limited marine biosphere. This result may also suggest that Earth-like exoplanets near the outer edge of the habitable zone are preferable for the phosphorus-limited marine biosphere to maintain the high atmospheric oxygen levels. The decrease in $p \mathrm{CO}_{2}$ due to the large solar luminosity also promotes the formation of the hydrocarbon haze when $\mathrm{CO}_{2}$ outgassing rate is low (black-shaded area in Fig. 5B), which is consistent with previous study of the biosphere evolution on a future Earth, which suggests formation of an organic haze layer in the future atmosphere (Ozaki and Reinhard 2021) (Fig. 5B).

The dependence of atmospheric oxygen levels on anoxygenic photoautotroph activity is shown in Fig. $5 \mathrm{C}$. The $\mathrm{CO}_{2}$ outgassing rate required for an abrupt increase in the atmospheric oxygen levels (thick blue line in Fig. 5C) increases with the anoxygenic photoautotroph activity. With more than $\sim 1.6 \times 10^{11} \mathrm{~mol} \mathrm{C}$ year $^{-1}$ of $F_{\text {red }}$, the abrupt increase in oxygen levels does not occur even 

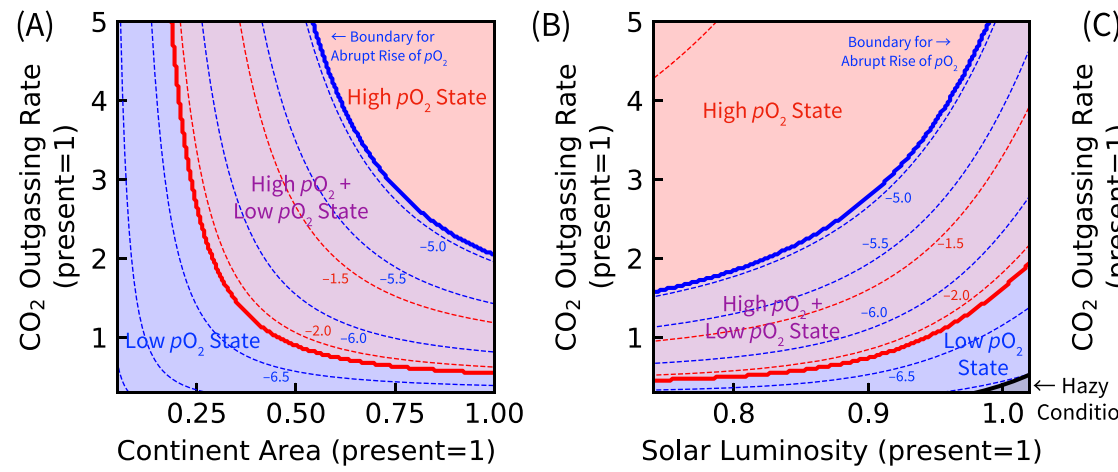

Solar Luminosity (present $=1$ )

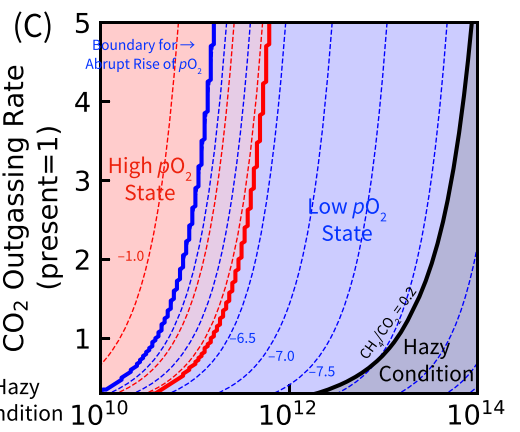

Primary Productivity of Anaerobic Photoautotroph

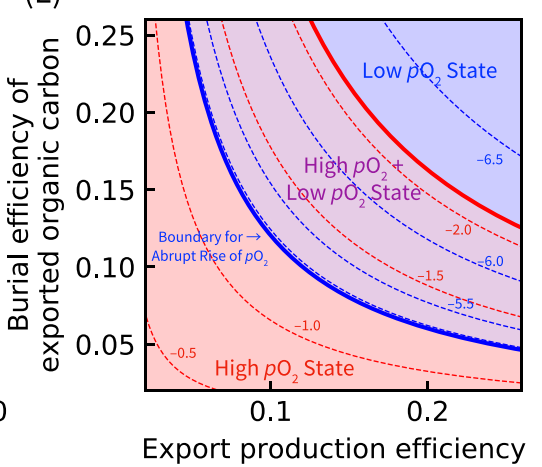
$\left(\mathrm{mol} \mathrm{C} \mathrm{yr}^{-1}\right)$

(F)

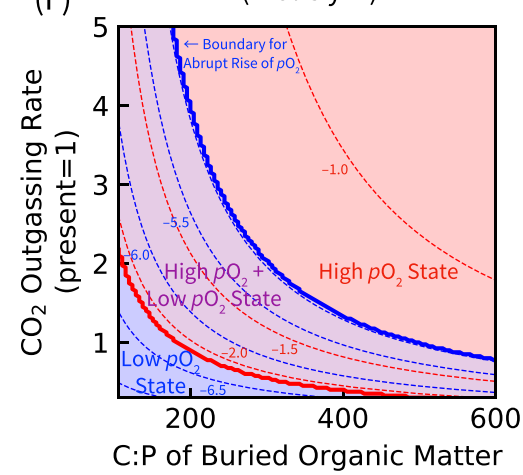

Fig. 5 Dependencies of atmospheric oxygen level on various parameters. Response of atmospheric oxygen levels in the parameter space of $\mathbf{A}$ continental area vs. $\mathrm{CO}_{2}$ outgassing rate; $\mathbf{B}$ solar luminosity vs. $\mathrm{CO}_{2}$ outgassing rate; $\mathbf{C}$ the primary productivity of anaerobic photoautotrophs $\left(F_{\text {red }}\right)$ vs. $\mathrm{CO}_{2}$ outgassing rate; $\mathbf{D}$ fraction of bioavailable phosphorus vs. primary productivity of anaerobic photoautotrophs; $\mathbf{E}$ burial efficiency of the exported organic carbon ( $a$ ) vs. export production efficiency $\left(f_{\mathrm{po}}\right)$, and $\mathbf{F} \mathrm{C}: \mathrm{P}$ ratio of organic matter buried in sediment vs. $\mathrm{CO}_{2}$ outgassing rate. Parameters are varied from the condition of $F_{\text {red }}$ of $7.50 \times 10^{10} \mathrm{~mol} \mathrm{C} \mathrm{year}^{-1}$, bioavailable fraction of the riverine phosphorus $\left(\gamma_{\mathrm{bio}}=1\right)$, solar luminosity of $83 \%$ of the present Earth, $\mathrm{CO}_{2}$ outgassing rate of present outgassing rate $\left(6.7 \times 10^{12} \mathrm{~mol} C\right.$ year $\left.{ }^{-1}\right)$, seafloor spreading rate of 1.307 times the present rate, C:P ratio of organic matter buried in sediment $\left(R_{c p, b u r}\right)$ of 300 , burial efficiency of the exported organic carbon ( $(a)$ of 0.2 , export production efficiency $\left(f_{\text {po }}\right)$ of 0.1 , and soil biological activity $\left(f_{\mathrm{e}}\right)$ of 0.15 . The areas filled with red and blue colors represent the conditions where high $\mathrm{O}_{2}$ levels $\left(>\sim 10^{-2} \mathrm{PAL}\right)$ and low $\mathrm{O}_{2}$ levels $\left(<\sim 10^{-5} \mathrm{PAL}\right)$ exist, respectively. Thin red/blue dashed line is the contour of the atmospheric oxygen level (PAL). Thick blue and red lines represent the conditions for the transition from the low $\mathrm{pO}_{2}$ state to high $p \mathrm{O}_{2}$ state and vice versa, respectively. Thick black line and grey-shaded areas represent the condition of haze formation $\left(\mathrm{CH}_{4} / \mathrm{CO}_{2}>0.2\right)$

when the $\mathrm{CO}_{2}$ outgassing rate reaches $\sim 5$ times the present level. Under the high $F_{\text {red }}$ condition, $p \mathrm{O}_{2}$ remains low because anoxygenic photoautotrophs consume riverine phosphorus (Ozaki et al. 2019; Olejarz et al. 2021), and because high $p \mathrm{CH}_{4}$ (and low $p \mathrm{CO}_{2}$ ) keeps the riverine phosphorus input rate low (Fig. 2E-H). Assuming that $F_{\text {red }}$ is conducted by Fe-based photoautotrophs, this critical level of $F_{\text {red }}\left(\sim 6.4 \times 10^{11}\right.$ mol Fe year $\left.^{-1}\right)$ is comparable with the minimum estimates of iron supply rate based on the deposition rate of Hamersley banded iron formations in the late Archean to the early Proterozoic $\left(5 \times 10^{11} \mathrm{~mol}\right.$ Fe year ${ }^{-1}$ ) (Holland 2006). Considering that the primary productivity of $\mathrm{H}_{2}$-based photoautotrophs is also important before the GOE (Kharecha et al. 2005; Canfield et al. 2006; Ozaki et al. 2018), the large $F_{\text {red }}$ might have maintained low $p \mathrm{O}_{2}$ before the GOE, even under the condition of a large volcanic $\mathrm{CO}_{2}$ outgassing rate. We expect that the activity of anoxygenic photoautotrophs decreases as the activity of oxygenic photosynthesis increases owing to the oxygenation of electron donors (e.g., $\mathrm{H}_{2}$ and $\mathrm{Fe}^{2+}$ ); therefore, the value of $F_{\text {red }}$ might have become smaller in the early Proterozoic before the GOE.

The critical condition of the high- $\mathrm{O}_{2}$ solution is also dependent on the fraction of bioavailable phosphorus, which is affected by the removal of phosphorus via inorganic compounds (e.g., absorption of phosphorus to $\mathrm{Fe}(\mathrm{III})$ minerals) (Fig. 5D). In addition, this critical condition is also dependent on the burial efficiency of organic carbon and the C:P ratio of the buried organic matter which could be much higher than the Redfield ratio (C:P 106:1) in anoxic marine conditions (Fig. 5E-F) (e.g., Algeo and Ingall 2007; Reinhard et al. 2017; Kipp and Stüeken 2017; Laakso and Schrag 2019). Because the burial rate of organic carbon and the inorganic removal 
rate of phosphorus in the ocean and sediments are also dependent on marine redox conditions, the biogeochemical conditions causing the abrupt rise of atmospheric oxygen should be evaluated using a more sophisticated biogeochemical model, that resolves the vertical profiles of the processes such as burial of organic carbon and the adsorption of phosphorus to Fe(III) minerals in the ocean.

\section{Conclusions}

In this paper, we reveal the possible relationship between continental growth and atmospheric evolution. We showed that the changes in the relative contribution between land and seafloor weathering affects phosphorus input, and that the atmosphere could evolve totally different redox conditions depending on the structure of the marine ecosystem and the $\mathrm{CO}_{2}$ outgassing flux. The conditions with lower solar luminosity and larger land fraction are preferable for the phosphorus-limited marine biosphere to achieve high oxygen levels in the atmosphere. However, the atmospheric oxygen level is strongly affected by the activity of the anaerobic marine microbial ecosystem. Nevertheless, our results suggest that the existence of continental crusts is crucial for achieving high oxygen levels with a phosphorus-limited marine biosphere.

Oxygen is a potential biosignature for Earth-like planets, with strong absorption bands detectable by transmission observations and future direct-imaging missions (e.g., Rothman et al. 2013; Meadows et al. 2018). Therefore, understanding how atmospheric oxygen could be built up biotically or abiotically is crucial to inform upcoming direct-imaging missions with coronagraphs. Recently, the importance of continents and their relationship to atmospheric oxygen levels has received attention (e.g., Olson et al. 2020; Glaser et al. 2020). Planets with large ocean masses are suggested to have important habitable planetary conditions (e.g., Olson et al. 2020; Glaser et al. 2020; Hayworth and Foley 2020). In these waterworlds, with a limited phosphorus to the ocean, the anaerobic microbial ecosystem might be as crucial as on the early Earth. However, even if oxygen is not detected in a planetary atmosphere, it does not mean that there are no oxygenic photosynthetic organisms in the marine ecosystem, regardless of the size of continents, as was the case for the early Earth before the GOE. Our results provide a fundamental understanding for processes in Earth-like planets with an Earth-like marine ecosystem, and would help constrain the observable biosignatures for future direct-imaging missions.

\section{Abbreviations}

PAL: Present atmospheric level; GOE: Great oxidation event.

\section{Supplementary Information}

The online version contains supplementary material available at https://doi. org/10.1186/s40623-021-01527-9.

Additional file 1: Supplementary Text that describes the temperature parameterization, Supplementary Figures that describes the dependency of the result on parameters associated with weathering, and Supplementary Tables that summarizes the values of parameters.

\section{Acknowledgements}

We thank two anonymous reviewers for providing constructive comments to improve the original manuscript. We thank Takeshi Sagiya and Hidenori Genda for handling this paper. We also thank Kazumi Ozaki and Satoshi Takahashi for fruitful discussions. We thank Tara Penner, MSc, from Edanz Group (https://enauthor-services.edanzgroup.com/) for editing a draft of this manuscript.

\section{Authors' contributions}

YW: conceptualization, formal analysis, funding acquisition, methodology, software, visualization, writing —original draft, writing—review and editing. ET: methodology, supervision, writing - review and editing. All authors read and approved the final manuscript.

\section{Funding}

YW was supported by Grant-in-aid for JSPS Research Fellow Number 20J12951.

\section{Availability of data and materials}

The numerical codes will be available from the corresponding author upon reasonable request.

\section{Declarations}

Ethics approval and consent to participate

Not applicable.

\section{Consent for publication}

Not applicable.

\section{Competing interests}

The authors declare no competing financial interests.

Received: 6 July 2021 Accepted: 5 October 2021

Published online: 18 October 2021

\section{References}

Algeo TJ, Ingall E (2007) Sedimentary $C_{\text {org: }}$ : P ratios, paleocean ventilation, and Phanerozoic atmospheric $\mathrm{P}_{\mathrm{O} 2}$. Palaeogeogr Palaeoclimatol Palaeoecol 256:130-155

Arney G, Domagal-Goldman SD, Meadows VS et al (2016) The pale orange dot: the spectrum and habitability of hazy archean earth. Astrobiology 16:873-899

Berner RA (1994) GEOCARB II: a revised model of atmospheric $\mathrm{CO}_{2}$ over phanerozoic time. Am J Sci 294:56-91

Betts JN, Holland HD (1991) The oxygen content of ocean bottom waters, the burial efficiency of organic carbon, and the regulation of atmospheric oxygen. Glob Planet Change 97:5-18

Canfield DE, Rosing MT, Bjerrum C (2006) Early anaerobic metabolisms. Philos Trans R Soc B 361:1819-1834

Catling DC, Zahnle KJ (2020) The Archean atmosphere. Sci Adv 6(9):eaax1420

Catling DC, Zahnle KJ, McKay CP (2001) Biogenic methane, hydrogen escape, and the irreversible oxidation of early Earth. Science 293(5531):839-843

Claire MW, Catling DC, Zahnle KJ (2006) Biogeochemical modelling of the rise in atmospheric oxygen. Geobiology 4:239-269

Coogan LA, Dosso SE (2015) Alteration of ocean crust provides a strong temperature dependent feedback on the geological carbon cycle and is 
a primary driver of the Sr-isotopic composition of seawater. Earth Planet Sci Lett 415:38-46

Cox GM, Lyons TW, Mitchell RN et al (2018) Linking the rise of atmospheric oxygen to growth in the continental phosphorus inventory. Earth Planet Sci Lett 489:28-36

Daines SJ, Lenton TM (2016) The effect of widespread early aerobic marine ecosystems on methane cycling and the Great Oxidation. Earth Planet Sci Lett 434:42-51

Drever Jl, Zobrist J (1992) Chemical weathering of silicate rocks as a function of elevation in the southern Swiss Alps. Geochim Cosmochim Acta 56:3209-3216

Eguchi J, Seales J, Dasgupta R (2020) Great Oxidation and Lomagundi events linked by deep cycling and enhanced degassing of carbon. Nat Geosci 13(1):71-76

Field CB, Behrenfeld MJ, Randerson JT et al (1998) Primary production of the biosphere: integrating terrestrial and oceanic components. Science 281 (5374):237-240

Flament N, Coltice N, Rey PF (2013) The evolution of the ${ }^{87} \mathrm{Sr} /{ }^{86} \mathrm{Sr}$ of marine carbonates does not constrain continental growth. Precambr Res 229:177-188

Gaillard F, Scaillet B, Arndt NT (2011) Atmospheric oxygenation caused by a change in volcanic degassing pressure. Nature 478:229-232

Glaser DM, Hartnett HE, Desch SJ et al (2020) Detectability of life using oxygen on pelagic planets and water worlds. ApJ 893:163

Godderis Y, Veizer J (2000) Tectonic control of chemical and isotopic composition of ancient oceans; the impact of continental growth. Am J Sci 300:434-461

Goldblatt C, Lenton TM, Watson AJ (2006) Bistability of atmospheric oxygen and the great oxidation. Nature 443:683-686

Gregory BS, Claire MW, Rugheimer S (2021) Photochemical modelling of atmospheric oxygen levels confirms two stable states. Earth Planet Sci Lett 561:116818

Hao J, Knoll AH, Huang F et al (2020a) Cycling phosphorus on the Archean Earth: Part I. Continental weathering and riverine transport of phosphorus. Geochim Cosmochim Acta 273:70-84

Hao J, Knoll AH, Huang F et al (2020b) Cycling phosphorus on the Archean Earth: Part II. Phosphorus limitation on primary production in Archean ecosystems. Geochim Cosmochim Acta 280:360-377

Haqq-Misra JD, Domagal-Goldman SD, Kasting PJ, Kasting JF (2008) A revised, hazy methane greenhouse for the Archean Earth. Astrobiology 8:1127-1137

Harada M, Tajika E, Sekine Y (2015) Transition to an oxygen-rich atmosphere with an extensive overshoot triggered by the Paleoproterozoic snowball Earth. Earth Planet Sci Lett 419:178-186

Hawkesworth CJ, Kemp AIS (2006) Evolution of the continental crust. Nature 443:811-817

Hayworth BPC, Foley BJ (2020) Waterworlds may have better climate buffering capacities than their continental counterparts. ApJL 902:L10

Holland HD (2006) The oxygenation of the atmosphere and oceans. Philos Trans R Soc B 361:903-915

Izon G, Zerkle AL, Williford KH et al (2017) Biological regulation of atmospheric chemistry en route to planetary oxygenation. Proc Natl Acad Sci 114:E2571-E2579

Kadoya S, Catling DC, Nicklas RW et al (2020) Mantle data imply a decline of oxidizable volcanic gases could have triggered the great oxidation. Nat Commun 11:2774

Kasting JF (2013) What caused the rise of atmospheric $\mathrm{O}_{2}$ ? Chem Geol 362:13-25

Kharecha P, Kasting J, Siefert J (2005) A coupled atmosphere-ecosystem model of the early Archean Earth. Geobiology 3:53-76

Kipp M, Krissansen-Totton J, Catling DC (2020) High burial efficiency is required to explain mass balance in Earth's early carbon cycle. Global Biogeochem Cycles 35(2).

Kipp MA, Stüeken EE (2017) Biomass recycling and Earth's early phosphorus cycle. Sci Adv 3(11):eaao4795

Korenaga J, Planavsky NJ, Evans DAD (2017) Global water cycle and the coevolution of the Earth's interior and surface environment. Philos Trans R Soc A 375:20150393

Krissansen-Totton J, Arney GN, Catling DC (2018) Constraining the climate and ocean $\mathrm{pH}$ of the early Earth with a geological carbon cycle model. Proc Natl Acad Sci 115:4105-4110
Krissansen-Totton J, Catling DC (2017) Constraining climate sensitivity and continental versus seafloor weathering using an inverse geological carbon cycle model. Nat Commun 8:15423

Kump LR (2008) The rise of atmospheric oxygen. Nature 451:277-278

Kump LR, Barley ME (2007) Increased subaerial volcanism and the rise of atmospheric oxygen 2.5 billion years ago. Nature 448:1033-1036

Laakso TA, Schrag DP (2019) A small marine biosphere in the Proterozoic Geobiology 17:161-171

Lee C-TA, Yeung LY, McKenzie NR et al (2016) Two-step rise of atmospheric oxygen linked to the growth of continents. Nat Geosci 9:417-424

Lehmer OR, Catling DC, Krissansen-Totton J (2020) Carbonate-silicate cycle predictions of Earth-like planetary climates and testing the habitable zone concept. Nat Commun 11:6153

Lenton TM, Dahl TW, Daines SJ et al (2016) Earliest land plants created modern levels of atmospheric oxygen. Proc Natl Acad Sci 113:9704-9709

Lyons TW, Reinhard CT, Planavsky NJ (2014) The rise of oxygen in Earth's early ocean and atmosphere. Nature 506:307-315

Meadows VS, Reinhard CT, Arney GN et al (2018) Exoplanet biosignatures: understanding oxygen as a biosignature in the context of its environment. Astrobiology 18:630-662

Olejarz J, Iwasa Y, Knoll AH, Nowak MA (2021) The Great Oxygenation Event as a consequence of ecological dynamics modulated by planetary change. Nat Commun 12:3985

Olson SL, Jansen M, Abbot DS (2020) Oceanographic considerations for exoplanet life detection. Astrophys J 895:19

Ozaki K, Reinhard CT (2021) The future lifespan of Earth's oxygenated atmosphere. Nat Geosci 14:138-142

Ozaki K, Tajika E, Hong PK et al (2018) Effects of primitive photosynthesis on Earth's early climate system. Nat Geosci 11:55-59

Ozaki K, Thompson KJ, Simister RL et al (2019) Anoxygenic photosynthesis and the delayed oxygenation of Earth's atmosphere. Nat Commun 10:3026

Pavlov AA, Brown LL, Kasting JF (2001) UV shielding of $\mathrm{NH}_{3}$ and $\mathrm{O}_{2}$ by organic hazes in the Archean atmosphere. J Geophys Res Planets 106:23267-23287

Paytan A, McLaughlin K (2007) The oceanic phosphorus cycle. Chem Rev 107:563-576

Reinhard CT, Planavsky NJ, Gill BC et al (2017) Evolution of the global phosphorus cycle. Nature 541:386-389

Riebe CS, Kirchner JW, Finkel RC (2004) Erosional and climatic effects on longterm chemical weathering rates in granitic landscapes spanning diverse climate regimes. Earth Planet Sci Lett 224:547-562

Rothman LS, Gordon IE, Babikov Y et al (2013) The HITRAN2012 molecular spectroscopic database. J Quant Spectrosc Radiat Transf 130:4-50

Sarmiento JL, Gruber N (2002) Sinks for anthropogenic carbon. Phys Today 55(8):30-36

Taylor SR, McLennan SM (1995) The geochemical evolution of the continental crust. Rev Geophys 33:241

Tyrrell T (1999) The relative influences of nitrogen and phosphorus on oceanic primary production. Nature 400:525-531

Walker JCG, Hays PB, Kasting JF (1981) A negative feedback mechanism for the long-term stabilization of Earth's surface temperature. J Geophys Res 86:9776

Wheat CG, Feely RA, Mottl MJ (1996) Phosphate removal by oceanic hydrothermal processes: an update of the phosphorus budget in the oceans. Geochim Cosmochim Acta 60(19):3593-3608

Yamanaka Y, Tajika E (1996) The role of the vertical fluxes of particulate organic matter and calcite in the oceanic carbon cycle: Studies using an ocean biogeochemical general circulation model. Global Biogeochem Cycles 10:361-382

Zerkle AL, Claire MW, Domagal-Goldman SD et al (2012) A bistable organicrich atmosphere on the Neoarchaean Earth. Nat Geosci 5:359-363

\section{Publisher's Note}

Springer Nature remains neutral with regard to jurisdictional claims in published maps and institutional affiliations. 